\title{
Bronchopulmonary dysplasia: incidence and risk factors
}

Pablo H. Brener Dik, M.D. ${ }^{a}$, Yeimy M. Niño Gualdron, M.D. ${ }^{a}$, María F. Galletti, M.D. ${ }^{a}$, Carolina M. Cribioli, M.D. ${ }^{a}$ and Gonzalo L. Mariani, M.D. ${ }^{a}$

\begin{abstract}
Introduction. Bronchopulmonary dysplasia is the most common chronic pulmonary sequela among very low birth weight infants. The objective of this study was to estimate its incidence in our Neonatal Unit over the past 5 years and analyze associated risk factors.

Population and methods. An observational and analytical study was conducted in a retrospective cohort, using data obtained from a prospective database of infants born at Hospital Italiano de Buenos Aires with a birth weight of less than 1500 grams between January 2010 and December 2014. The incidence of bronchopulmonary dysplasia and its association with several secondary outcome measures were studied.

Results. Two hundred and forty-five patients were included. The incidence of moderate/ severe bronchopulmonary dysplasia was $22 \%$, and it was associated with a younger gestational age and lower birth weight. A significant association was observed with surfactant use, mechanical ventilation requirement, and length of mechanical ventilation. Patients with moderate/severe bronchopulmonary dysplasia had a higher incidence of patent ductus arteriosus and late-onset sepsis. A lower birth weight (adjusted odds ratio [aOR]: 0.99, 95\% confidence interval [CI]: 0.991-0.997, $p<0.001$ ) and the length of mechanical ventilation (aOR: 1.08, 95\% CI: 1.01-1.15, $p<0.01$ ) remained associated following adjustment for other outcome measures. In addition, an association was observed among patients with intrauterine growth restriction born at less than 32 weeks of gestational age (OR: 4.71, 95\% CI: 1.68-13.2). Conclusions. Theincidenceofbronchopulmonary dysplasia in our unit was associated with a lower birth weight and the length of mechanical ventilation. Among infants born at less than 32 weeks of gestation, intrauterine growth restriction accounted for an additional risk.

Key words: bronchopulmonary dysplasia, preterm infant, mechanical ventilation.
\end{abstract}

http:/ / dx.doi.org/10.5546/ aap.2017.eng.476

E-mail address:

Pablo Brener Dik, M.D.: pablo.brener@hiba.org.ar

Funding:

None.

Conflict of interest:

None.

Received: 10-11-2016

Accepted: 3-6-2017
To cite: Brener Dik PH, Niño Gualdron YM, Galletti MF, et al. Bronchopulmonary dysplasia: incidence and risk factors. Arch Argent Pediatr 2017;115(5):476-482.

\section{INTRODUCTION}

Advances made in perinatal care over the past two decades have contributed to increase the rate of survival among very low birth weight newborn infants (NBIs). ${ }^{1,2}$ One of the major challenges in current neonatology is to continue reducing mortality without increasing the resulting complications..$^{1,2}$ Respiratory morbidity associated with prematurity has not decreased alongside the improvement in other neonatal adverse outcomes. ${ }^{1}$ Bronchopulmonary dysplasia (BPD) is the most common pulmonary sequela in this population and is associated with several risk factors that, together with immature airways, result in an altered airway and pulmonary capillary development, thus causing a varying degree of limited pulmonary function. . $^{3,4}$

Major efforts are made both in the context of research and perinatal care as an attempt to reduce the incidence of BPD by means of different strategies: maternal management (tocolytic agents and antenatal corticosteroids), improved attendance at delivery (route and initial stabilization), neonatal drugs (surfactant, vitamin A, corticosteroids, caffeine, etc.), new ventilation modes, management of nosocomial infections, improved nutritional aspects, etc. ${ }^{5-7}$ Given that BPD is the most common cause of respiratory morbidity among preterm NBIs surviving the neonatal period, it is very interesting to establish its incidence in neonatal units and also identify risk factors in these infants. However, both the incidence of BPD and its associated risk factors may change over time, once strategies mentioned here are 
implemented. ${ }^{7,8}$ Although there is a very extensive and plenty bibliography available in this field, ${ }^{3,8-11}$ it is important to conduct a periodic review of BPD incidence and its risk factors in each neonatal unit to reassess prevention strategies.

The objective of this study was to estimate the incidence of BPD among infants born with a weight of less than 1500 grams at our Neonatal Unit over the past 5 years and analyze associated risk factors.

\section{MATERIAL AND METHODS}

Design: Observational and analytical study conducted in a retrospective cohort.

Population: All live NBIs born at Hospital Italiano de Buenos Aires with a birth weight of less than 1500 grams in the period between January $1^{\text {st }}, 2010$ and December 31 $1^{\text {st }}, 2014$ were included. Patients for whom the primary outcome measure was missing from the secondary database were excluded.

Data collection: For this study, data were obtained from a secondary preterm NBI database. This group of patients born at Hospital Italiano de Buenos Aires is included in the Neocosur Neonatal Network database, ${ }^{12}$ which includes preterm infants with a birth weight of less than 1500 grams, regardless of their gestational age (GA). Demographic outcome measures and clinical outcomes are recorded prospectively and systematically. For this study, the following outcome measures were collected and analyzed: multiple pregnancy, intrauterine growth restriction (IUGR), defined as growth below the $3^{\text {rd }}$ percentile as per Fenton's growth curves, full course of antenatal corticosteroids, chorioamnionitis, GA, birth weight (BW), Apgar score at 5 minutes, sex, use of oxygen, use of continuous positive airway pressure (CPAP), use of assisted mechanical ventilation (AMV), use of high frequency oscillatory ventilation (HFOV), days of AMV, use of pulmonary surfactant (at least one dose), sepsis, necrotizing enterocolitis (NEC) greater than or equal to Bell's stage II, treated patent ductus arteriosus (PDA).

Primary outcome measure: BPD recorded as dichotomous outcome measure. It was defined as a fraction of inspired oxygen $\left(\mathrm{FiO}_{2}\right)$ greater than 0.21 over 28 days. The presence of moderate/ severe BPD with oxygen requirement at 36 weeks old among survivors was also recorded. Deceased patients were excluded from the analysis to establish its association with other outcome measures. Most prospective clinical trials use the combined outcome of BPD and/or death

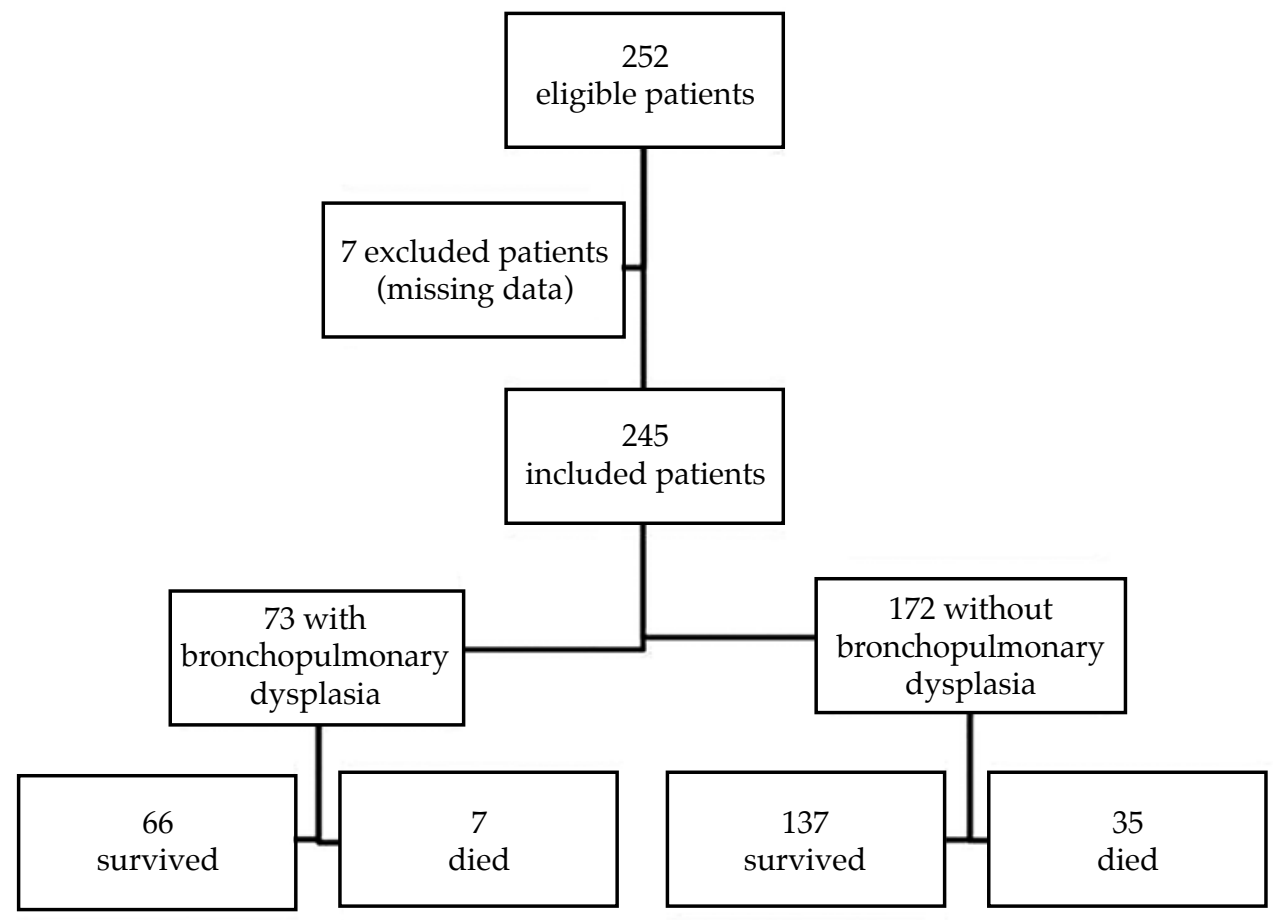


because they compete with one another. Preterm infants who die early will not develop BPD. Low BPD rates at any given site may mean a very high mortality rate; on the contrary, sites with a low mortality rate may show higher BPD rates. If deceased patients had been included, the association with certain risk factors may have resulted in a false underestimation (including protection).

Statistical analysis: Measures of central tendency and dispersion were estimated for continuous outcome measures and, based on their distribution, they were reported as mean and standard deviation or as median and interquartile range. Measures of frequency were estimated for dichotomous outcome measures; they were reported as percentages. BPD incidence and mortality rate were estimated. A univariate analysis was performed to study the association among the primary outcome measure and the other outcome measures recorded in the study. The Student's t test or the Mann-Whitney test were used (depending on distribution) to analyze continuous outcome measures, and the $\chi^{2}$ test was used for dichotomous outcome measures. Lastly, a multivariate logistic regression analysis was done to establish independent outcome measures associated with BPD, and adjusting them as per other outcome measures included in this study that resulted statistically significant in the univariate analysis. All $p$ values $<0.05$ were considered significant, and the analyses were done using the STATA 13 software.

Ethical considerations: The study protocol was approved in May 2016 by the site's Ethics Committee for Research Protocols.

\section{RESULTS}

During the study period, 252 patients who met eligibility criteria were born at our hospital. Seven patients were excluded because data for the primary outcome measure were missing, so 245 patients were included in the study (see Figure 1). The characteristics of the population are presented in Table 1. A total of 73 patients complied with our defined primary outcome measure; therefore, the incidence of BPD was $29.7 \%$. The incidence of moderate/severe BPD among survivors was $22 \%$. Forty-two patients died over the study period; this means overall mortality was $17.1 \%$. Once deceased patients were excluded, 203 patients were included in the analysis to find an association between BPD and risk factors.
Univariate analyses were done to assess the association between risk factors and oxygen requirement at 28 days old and 36 weeks old. This analysis is described in Table 2. Moderate/ severe BPD showed a significant association with a younger GA, a lower BW, and male sex. Patients with moderate/ severe BPD showed a significantly higher use of CPAP, AMV, pulmonary surfactant, and HFOV, and their length of AMV was longer. They also had a significantly higher rate of sepsis and PDA. On the contrary, no association was observed with multiple pregnancy, IUGR, antenatal corticosteroids, chorioamnionitis or NEC. However, once the population was stratified by GA ( $<32$ weeks), the association with moderate/severe BPD was 4 times higher in the group of infants with IUGR than in the group of infants without this condition (odds ratio [OR]: 4.71, 95\% confidence interval [CI]: 1.6813.2). The group of patients with moderate/ severe BPD received caffeine more frequently (OR: 2.8, 95\% CI: 1.4-5.7) (the latter two analyses were done post hoc).

A multivariate logistic regression analysis was also done, which is described in Table 3. A lower BW and the length of AMV were significantly associated with moderate/severe BPD once data were adjusted for sex, AMV and surfactant requirement, having had PDA, and late-onset sepsis. Each day of mechanical ventilation

TABLE 1. Population demographic outcome measures

\begin{tabular}{|c|c|c|}
\hline \multicolumn{2}{|l|}{ Outcome measure } & \multirow{2}{*}{$\begin{array}{c}\begin{array}{c}\text { Overall population } \\
(\mathbf{n}=\mathbf{2 4 5 )}\end{array} \\
28.8 \pm 2.9\end{array}$} \\
\hline GA (weeks) & mean $\pm S D$ & \\
\hline BW (grams) & mean $\pm S D$ & $1058 \pm 284$ \\
\hline Female sex & $\mathrm{n}(\%)$ & $123(50.2)$ \\
\hline Twins & $\mathrm{n}(\%)$ & $93(38)$ \\
\hline $\begin{array}{l}\text { Chorioamnionitis* } \\
\text { (studied } \mathrm{n}=134 \text { ) }\end{array}$ & $\mathrm{n}(\%)$ & $20(15)$ \\
\hline $\begin{array}{l}\text { Antenatal corticosteroids } \\
\text { (studied } \mathrm{n}=232 \text { ) }\end{array}$ & $\mathrm{n}(\%)$ & $194(86)$ \\
\hline IUGR & $\mathrm{n}(\%)$ & $61(25)$ \\
\hline $\begin{array}{l}\text { C-section* } \\
\text { (studied } n=243 \text { ) }\end{array}$ & $\mathrm{n}(\%)$ & $223(92)$ \\
\hline \multicolumn{2}{|c|}{ Apgar score at $5 \mathrm{~m}$, median (IQR) } & $8(7-9)$ \\
\hline \multicolumn{3}{|c|}{$\begin{array}{l}\text { GA: gestational age; BW: birth weight; } \\
\text { IUGR: intrauterine growth restriction; } \\
\text { SD: standard deviation; IQR: interquartile range. } \\
\text { * Studied n was lower than the study population due to data } \\
\text { missing from the secondary database. }\end{array}$} \\
\hline
\end{tabular}


increased the association with moderate/severe BPD by $8 \%$, regardless of the other outcome measures included in the model.

Finally, the group of deceased patients was analyzed $(n=42)$. Their GA was $26 \pm 3$ weeks and their BW was $729 \pm 239$ grams, both significantly lower to those of survivors $(p<0.001)$. Also, $98 \%$ of them required AMV, 91\% used surfactants, $60 \%$ had PDA, and 54\% developed late-onset sepsis. Only 7 patients died after having developed BPD.

\section{DISCUSSION}

BPD is a disease of multifactorial origin that mostly affects preterm infants, and is inversely proportional to GA and BW. ${ }^{3,4}$ The progressive increase in survival of very low birth weight infants has resulted in an increase in the number of infants at risk of developing BPD. ${ }^{1,2}$

In this study, the incidence rate of BPD in our Neonatal Unit is within the range described by other neonatal networks, although it may vary from one site to the other. The neonatal research network of the United States National Institutes of Health (NIH) reported an increase in the incidence of BPD (defined as oxygen requirement at 36 weeks) in the past 20 years and that it is above $40 \%$ among preterm infants born between 22 and 28 weeks of GA. ${ }^{1}$ In addition, a recent report of the South American Neocosur Neonatal Network reported a 25\% incidence of BPD (as defined above) among NBIs with a birth weight of less than 1500 grams. $^{2}$

Deceased patients were younger and more immature compared to those who survived. Their rates of AMV requirement, surfactant use, PDA and sepsis were higher, although their incidence of BPD was lower because they died before developing it. These data support the fact that they had to be excluded from the risk factor analysis. Otherwise, several factors associated with the primary outcome measure would have been considered protective factors.

It is important to identify the subgroup of patients with moderate/severe BPD because their

TABLE 2. Univariate analysis. Moderate/severe bronchopulmonary dysplasia. $N=203$

\begin{tabular}{|c|c|c|c|c|}
\hline Outcome measure & $\begin{array}{c}\text { With } \mathrm{O}_{2} \text { at } 36 \text { weeks } \\
(n=45)\end{array}$ & $\begin{array}{l}\text { Without } \mathrm{O}_{2} \text { at } 36 \text { weeks } \\
\qquad(\mathrm{n}=158)\end{array}$ & $P$ value & OR $(95 \% \mathrm{CI})$ \\
\hline $\begin{array}{l}\text { GA (weeks) } \\
\text { mean } \pm \text { SD }\end{array}$ & $27.15 \pm 2.3$ & $30.04 \pm 2.3$ & $0.001\left(^{*}\right)$ & NC \\
\hline $\begin{array}{l}\mathrm{BW}(\text { grams }) \\
\text { mean } \pm \mathrm{SD}\end{array}$ & $875 \pm 186$ & $1198 \pm 206$ & $0.001\left(^{*}\right)$ & NC \\
\hline Multiple pregnancy, n (\%) & $13(29)$ & $60(38)$ & $0.26(\mp)$ & $0.66(0.29-1.42)$ \\
\hline $\begin{array}{l}\text { Chorioamnionitis, }{ }^{*} \mathrm{n}(\%) \\
\text { (studied } \mathrm{n}=115)\end{array}$ & $7(23)$ & $10(12)$ & $0.12(\mp)$ & $2.28(0.64-7.49)$ \\
\hline $\begin{array}{l}\text { Antenatal corticosteroids, }{ }^{*} \mathrm{n}(\%) \\
\text { (studied } \mathrm{n}=193 \text { ) }\end{array}$ & $37(86)$ & $128(85)$ & $0.90(\mp)$ & $1.06(0.38-3.43)$ \\
\hline IUGR n $(\%)$ & $9(20)$ & $36(23)$ & $0.69(\mathrm{~F})$ & $0.85(0.32-2.01)$ \\
\hline Female sex, n $(\%)$ & $15(33)$ & $90(57)$ & $0.005(\mp)$ & $0.38(0.17-0.79)$ \\
\hline $\mathrm{O}_{2}$ requirement, $\mathrm{n}(\%)$ & $45(100)$ & $91(71)$ & $0.001(\mp)$ & $\mathrm{NC}$ \\
\hline AMV requirement, $\mathrm{n}(\%)$ & $36(80)$ & $73(46)$ & $0.001(\mp)$ & $4.6(2-11.6)$ \\
\hline $\mathrm{CPAP}$ requirement, $\mathrm{n}(\%)$ & $40(89)$ & $92(58)$ & $0.001(\mp)$ & $5.7(2-19.5)$ \\
\hline Surfactant requirement, n (\%) & $36(80)$ & $65(41)$ & $0.001(\mp)$ & $5.7(2.5-14.3)$ \\
\hline $\begin{array}{l}\text { Days of AMV } \\
\text { median (IQR 25-75) }\end{array}$ & $20.5(7-39)$ & $2.5(1-5.5)$ & $0.001(¥)$ & $\mathrm{NC}$ \\
\hline High frequency ventilation, $\mathrm{n}(\%)$ & $16(35)$ & $10(6)$ & $0.001(\mp)$ & $8.1(3-22)$ \\
\hline Late-onset sepsis, n (\%) & $21(52)$ & $32(30)$ & $0.015(\mp)$ & $2.5(1.09-5.6)$ \\
\hline Early sepsis, n (\%) & $4(8.9)$ & $0(0)$ & $0.001(\mp)$ & $\mathrm{NC}$ \\
\hline PDA, n $(\%)$ & $21(47)$ & $38(24)$ & $0.003(\mp)$ & $2.7(1.3-5.8)$ \\
\hline NEC, n $(\%)$ & $5(11)$ & $8(5)$ & $0.14(\mathrm{~F})$ & $2.3(0.5-8.6)$ \\
\hline
\end{tabular}

GA: gestational age; NA: not applicable; BW: birth weight; IUGR: intrauterine growth restriction; AMV: assisted mechanical ventilation; PDA: patent ductus arteriosus; NEC: necrotizing enterocolitis; $\mathrm{O}_{2}$ : oxygen.

$\left(^{*}\right)$ T test. ( $) \chi^{2}$ test. (¥) Mann-Whitney test.

* Studied $\mathrm{n}$ was lower than the study population due to data missing from the secondary database. 
prognosis is worse compared to those with mild BPD. ${ }^{13}$ For this reason, although analyses were done to look for associated risk factors in both subgroups, only results observed in patients with moderate/severe BPD were reported.

GA and BW were significantly lower among patients with BPD, as expected. BPD incidence was higher among male patients included in this study than girls, although such association was lost once adjustment for other outcome measures was done. It is known that male sex is associated with a higher morbidity and mortality in neonatology. ${ }^{14}$ Several prior studies showed that antenatal corticosteroids significantly reduced neonatal morbidity and mortality, but not chronic pulmonary disease.., 15 In our setting, a high rate of antenatal corticosteroid use was observed but there was no association with the primary outcome measure.

An interesting result of this article is that, once the overall population is analyzed, no association with IUGR was established. However, in the group of NBIs born at less than 32 weeks of GA, the association of IUGR and moderate/severe BPD was 4 times higher than in the group of infants without this condition. The association between IUGR and BPD has been reported in several groups. ${ }^{16-18}$ As a risk factor, IUGR is most likely less relevant among NBIs born at an older $\mathrm{GA}$, i.e. more mature infants, given that the latter outcome measure acts as a modifier of this association.

There is evidence of the role played by inflammation in BPD pathogenesis. This may be the result of a failure in the regulation and control of inflammatory response and, although controversial, chorioamnionitis may be a predisposing factor. ${ }^{11,19}$

TABLE 3. Multivariate analysis. Moderate/severe bronchopulmonary dysplasia. $N=203$

\begin{tabular}{lcc}
\hline Outcome measure & aOR $(\mathbf{9 5} \%$ CI) & P value \\
\hline BW & $0.994(0.991-0.997)$ & 0.001 \\
Female sex & $0.63(0.15-2.58)$ & 0.52 \\
AMV requirement & $0.85(0.11-6.26)$ & 0.87 \\
Surfactant requirement & $1.85(0.31-11.08)$ & 0.49 \\
Length of AMV & $1.08(1.01-1.15)$ & 0.02 \\
PDA & $0.63(0.13-3.01)$ & 0.57 \\
Late-onset sepsis & $0.59(0.14-2.53)$ & 0.48 \\
\hline
\end{tabular}

BW: birth weight; AMV: assisted mechanical ventilation; PDA: patent ductus arteriosus.
In our study, the rate of chorioamnionitis was twice as high among mothers of patients with BPD; however, such difference was not statistically significant. Systemic infection increases the levels of vasodilators, prostaglandins and other mediators that have been associated with an increase in the opening of PDA and an greater incidence of BPD., ${ }^{3,5,7,9-11}$ In our study, both outcome measures (inflammation, represented by sepsis, and PDA) were associated with BPD, although these results did not remain once the multivariate analysis was done.

For a long time, oxygen and AMV use have been considered the most important factors in the pathogenesis of BPD. ${ }^{20-22}$ The effect of hyperoxia on free radicals in preterm infants is favored by a reduction in antioxidative mechanisms in this group of infants. ${ }^{3,20,21}$

SUPPORT, a randomized study, compared two target ranges of oxygen saturation in preterm infants younger than 28 weeks throughout their hospitalization. ${ }^{23}$ The authors reported that, although a low target range (85-89\%) reduced the risk of retinopathy of prematurity and BPD, it was associated with a higher mortality. In addition, although BPD is uncommon in NBIs who did not require mechanical ventilation, at present, it has been observed in patients without baseline severe pulmonary disease. ${ }^{3-10,24}$ Excess tidal volume in each cycle leads to what is known as "volutrauma," which is characterized by overdistension of alveolar-capillary membrane, inflammatory reaction, interstitial edema, and surfactant inactivation. ${ }^{22}$ In our study, oxygen use as well as AMV and pulmonary surfactant use (as a manifestation of severity of baseline respiratory distress syndrome) were associated with BPD in the univariate analysis.

Over the past decade, "classical BPD", described over 40 years ago, ${ }^{25}$ has been progressively replaced by milder forms of chronic lung injury called "new BPD." $3,10,24$ The main characteristics of this new BPD include its developing in more immature infants with a lower BW, a lower number of alveoli and capillaries, and less aggressive mechanical ventilation with a lower oxygen requirement. ${ }^{3,10,24}$ This presentation has a better prognosis and less long-term sequelae, although its incidence has not decreased..$^{1,3,10}$ The population of patients with moderate/severe BPD analyzed in our study shares the characteristics of immaturity, which are reflected in mean GA and BW. Although more than $80 \%$ of patients in this group required 
AMV and pulmonary surfactant administration, it is worth noting that these two factors did not show an independent association with BPD whereas the length of mechanical ventilation did. Based on our data, it may be established that the length of AMV probably plays a relevant role and takes part in the pathogenesis of BPD. Our findings are consistent with those of Gagliardi et al., who analyzed 1260 NBIs with a birth weight of less than 1500 grams and found that the rate of baseline intubation was not associated with BPD and that long-term AMV was a risk factor associated with BPD. ${ }^{26}$ These findings encourage us to proactively advocate for early extubation, and to consider it since the very moment each preterm infant is put on mechanical ventilation.

The bibliography includes references to studies on drugs for the prevention of chronic pulmonary disease in preterm NBIs. ${ }^{6}$ A well-known study randomized more than 2000 preterm infants to receive caffeine or placebo and found that failure to administer caffeine when indicated increased the risk of BPD. ${ }^{27}$ As a conclusion, it is commonly said that caffeine should be administered to all preterm NBIs to prevent BPD, but this is a misinterpretation of the above-mentioned study. In our cohort, a significant association was observed between caffeine use and moderate/ severe BPD; however, this finding should be interpreted with the utmost caution because of our study's retrospective design. It is reasonable to consider that such association was the result of caffeine prescription in extremely preterm infants, who are at a higher risk of developing BPD.

Our study poses certain limitations and strengths. The availability of plenty bibliography on this topic may question the usefulness of this study. In any case, the incidence and risk factors of BPD and the management of these patients changes over time. A recent study even refutes present BPD definitions and proposes changing them to one that correlates with respiratory morbidity during infancy. ${ }^{28}$ So it seems necessary to conduct studies like this one to search for risk factors, either new or already known, to develop new prevention strategies, such as early extubation, to thus avoid unnecessary AMV use and reduce potential progression to chronic pulmonary disease. Given the study's retrospective and observational design, it is not possible to establish the causality between studied risk factors and BPD. However, the fact that the study used a secondary database with prospective data collection ensures a high level of data reliability and the inclusion of almost $100 \%$ of patients who met inclusion criteria. Therefore, a high level of veracity may be assumed at the time of weighting results. Taking into account that sometimes a prolonged use of assisted ventilation is required for the management of chronic pulmonary disease, the interpretation of our results may be hindered. However, considering the mean GA ( 27 weeks) and the interquartile range of AMV requirement (7-39 days) in our patients with BPD, it is more likely that such period has occurred before diagnosis, not after it.

To conclude, we established the incidence of BPD in our Neonatal Unit, and an association with several risk factors has been observed. A lower $\mathrm{BW}$ and the length of mechanical ventilation are independent risk factors for the development of moderate/severe BPD. Among infants born at less than 32 weeks of GA, the presence of IUGR is an additional outcome measure for risk.

\section{REFERENCES}

1. Stoll BJ, Hansen NI, Bell EF, et al. Trends in care practices, morbidity and mortality of extremely preterm neonates, 1993-2012. JAMA 2015;314(10):1039-51.

2. Fernández $\mathrm{R}, \mathrm{D} \square$ Apremont $\mathrm{I}$, Domínguez $\mathrm{M}$, et al. Supervivencia y morbilidad en recién nacidos de muy bajo peso al nacer en una Red Neonatal sudamericana. Arch Argent Pediatr 2014;112(5):405-12.

3. Bancalari A. Actualización en Presentación y Patogénesis de la Displasia Broncopulmonar. Rev Chil Pediatr 2009;80(3):213-24.

4. Sánchez Luna M, Moreno Hernando J, Botet Mussons F, et al. Displasia broncopulmonar: definiciones y clasificación. An Pediatr 2013;79(4):262.e1-6.

5. Greenough A, Ahmed N. Perinatal prevention of bronchopulmonary dysplasia. J Perinat Med 2013;41(1): 119-26.

6. Beam KS, Aliaga S, Ahlfeld SK, et al. A systematic review of randomized controlled trials for the prevention of bronchopulmonary dysplasia in infants. J Perinatol 2014;34(9):705-10.

7. Payne N, Finkelstein M, Liu M, et al. NICU Practices and Outcomes Associated With 9 Years of Quality Improvement Collaboratives. Pediatrics 2010;125(3):437-46.

8. Latini G, De Felice C, Giannuzzi R, et al. Survival rate and prevalence of bronchopulmonary dysplasia in extremely low birth weight infants. Early Hum Dev 2013;89(Suppl 1): S69-73.

9. Gursoy T, Hayran M, Derin H, et al. A Clinical Scoring System to Predict the Development of Bronchopulmonary Dysplasia. Am J Perinatol 2015;32(7):659-66.

10. Bancalari E, Claure N, Sosenko IR. Bronchopulmonary dysplasia: changes in pathogenesis, epidemiology and definition. Semin Neonatol 2003;8(1):63-71.

11. Speer C. Chorioamnionitis, Postnatal Factors and Proinflammatory Response in the Pathogenetic Sequence of Bronchopulmonary Dysplasia. Neonatology 2009;95(4): 353-61.

12. Grupo Colaborativo Neocosur. Very-low-birth-weight infant outcomes in 11 South American NICUs. J Perinatol 2002;22(1):2-7. 
13. Hirata K, Nishihara M, Shiraishi J, et al. Perinatal factors associated with long term respiratory sequelaein extremely low birthweight infants. Arch Dis Child Fetal Neonatal Ed 2015;100(4):F314-9.

14. Marshall G, Tapia J, D' Apremont I, et al. A New Score for Predicting Neonatal Very Low Birth Weight Mortality Risk in the NEOCOSURSouth American Network. J Perinatol 2005;25(9):577-82.

15. Roberts D, Dalziel S. Antenatal corticosteroids for accelerating fetal lung maturation for women at risk of preterm birth. Cochrane Database Syst Rev 2006;(3):CD004454.

16. Reiss I, Landmann E, Heckmann M, et al. Increased risk of bronchopulmonary dysplasia and increased mortality in very preterm infants being small for gestational age. Arch Gynecol Obstet 2003;269(1):40-4.

17. Eriksson L, Haglund B, Odlind V, et al. Perinatal conditions related to growth restriction and inflammation are associated with an increased risk of bronchopulmonary dysplasia. Acta Paediatr 2015;104(3):259-63.

18. Lal M, Manketlow B, Draper E, et al. Chronic Lung Disease of Prematurity and Intrauterine Growth Retardation: A Population-Based Study. Pediatrics 2003;111(3):483-7.

19. Ericson JE, Laughon MM. Chorioamnionitis: implications for the neonate. Clin Perinatol 2015;42(1):155-65.

20. Saugstad OD. Bronchopulmonary dysplasia and oxidative stress: are we closer to an understanding of the pathogenesis of BPD? Acta Paediatr 1997;86(12):1277-82.

21. Davis JM. Role of oxidant injury in the pathogenesis of neonatal lung disease. Acta Paediatr Suppl 2002;91(437):23-5.

22. Attar MA, Donn SM. Mechanisms of ventilator-induced lung injury in premature infants. Semin Neonatol 2002;7(5):353-60.

23. SUPPORT Study Group of the Eunice Kennedy Shriver NICHD Neonatal Research Network. Target Ranges of Oxygen Saturation in Extremely Preterm Infants. N Engl J Med 2010;362(21):1959-69.

24. Jobe A. The new bronchopulmonary dysplasia. Curr Opin Pediatr 2011;23(2):167-72.

25. Northway WH, Rosan RC, Porter DY. Pulmonary disease following respiratory therapy of hyaline membrane disease. Bronchopulmonary dysplasia. NEnglJMed 1967;276(7):35768.

26. Gagliardi L, Bellù R, Lista G, et al. Do differences in delivery room intubation explain different rates of bronchopulmonary dysplasia between hospitals? Arch Dis Child Fetal Neonatal Ed 2011;96(1):F30-5.

27. Schmidt B, Roberts R, Davis $P$, et al. Caffeine therapy for apnea of prematurity. N Engl J Med 2006;354(20):2112-21.

28. Poindexter B, Feng R, Schdmidt B, et al. Comparisons and limitations of current definitions of Bronchopulmonary dysplasia for the prematurity and respiratory outcomes program. Ann Am Thorac Soc 2015;12(12):1822-30. 